\title{
IDENTIDADE EM CRISE: A DÉCADA DE 1930 E SEUS REFLEXOS NA OBRA DE GRACILIANO RAMOS
}

Palavras-chave: Cultura; Língua; Iconicidade verbal; Identidade; Literatura.

\section{Palavras iniciais}

A hipótese em torno da qual se concentra o esforço investigativo desta tese é a de que os romances de Graciliano Ramos publicados na década de 1930, São Bernardo (1934), Angústia (1936) e Vidas Secas (1938), apontam uma crise de identidade desencadeada no homem sertanejo durante a década de 1930. Os acontecimentos sóciohistóricos desse período, especialmente os que fizeram parte da política de Governo do Presidente Getúlio Vargas - cuja culminância ocorre com a implantação do Estado Novo, vigente no período de 1937 a 1945 - já vinham produzindo efeitos na identidade do povo e no tecido social.

Em função da abrangência do tema e dos vários elementos que contribuíram para a configuração do presente estudo, foi necessário o diálogo interdisciplinar com outras áreas do conhecimento para melhor compreensão. Desse modo, as considerações e os 
resultados das investigações foram compartimentados para facilitar a leitura. Primeiramente, apresentou-se um panorama histórico do período de referência, com o objetivo de localizar historicamente algumas afirmações feitas. Em seguida, a análise cuidadosa das especificidades do tema central: identidade, a partir das considerações de autores renomados, estudiosos desse assunto. Também foram tratadas questões de Literatura, visto a importância do corpus de análise na composição literária do cânone nacional.

O tema identidade tem levantado alguns debates em vários meios científicos. Segundo Stuart Hall (2006), alguns eventos globais como o feminismo, a psicanálise e a globalização são fatores que têm exercido influência direta no modo de se compreender esse fenômeno, provocando mudança de paradigma em torno do assunto. Essa mudança é uma das causas apontadas para o maior interesse dos pesquisadores acerca do assunto.

Entende-se a construção da identidade como um processo que se desenvolve em torno do sentimento de identificação e de pertencimento a partir, basicamente, de três dimensões: em relação a si mesmo, em relação ao outro e em relação à sociedade. Essa construção, no entanto, nem sempre ocorre de forma tranquila, senão no confronto com os acontecimentos e no embate das emoções. Quando grandes transformações atingem qualquer uma dessas dimensões há uma ruptura e, possivelmente, instala-se uma crise de identidade.

A ideia de crise encontra respaldo na tese defendida por Hall em Identidade cultural na pós-modernidade (2006). Nesse texto, o autor fala do descentramento do sujeito moderno, cuja causa estaria em cinco grandes avanços das teorias sociais e das ciências humanas: os reflexos da teoria marxista, o impacto do feminismo, a descoberta do inconsciente por Freud, os estudos saussurianos e o "poder disciplinar" de Foucault. 
Em outra obra, acerca da necessidade do debate em torno do tema identidade, o pesquisador destaca que

Está-se efetuando uma completa desconstrução das perspectivas identitárias em uma variedade de áreas disciplinares, todas as quais, de uma forma ou outra, criticam a ideia de identidade integral, originária e unificada (...). Onde está, pois, a necessidade de mais uma discussão sobre a "identidade"? Quem precisa dela? (HALL, 2017, p. 103)

$\mathrm{Na}$ esteira desses questionamentos, cabe esclarecer a escolha do tema Identidade numa investigação cujo fim é a Língua Portuguesa. Considerando que a linguagem é o principal modo de expressão, de interação, de leitura e de representação do mundo, e que o texto literário reflete um dado momento histórico-cultural, defende-se o desenvolvimento de estudos em torno do tema Identidade, a fim de que se possa delinear o modo como ocorrem os processos de formação e seus reflexos, tanto na prática linguageira, quanto na produção de textos literários. Em última análise, a fala de Hall aponta para uma necessidade que alcança os bancos escolares, uma vez que esse é o ambiente, por essência, de formação de leitores cujo gosto pela literatura carece de despertamento, a ser fomentado pelo professor. Nesse cenário, o texto literário é um rico representante de identidades diversas percebidas no tecido social. Nesse sentido, Simões afirma ser observável

a seleção vocabular como representativa de usos e costumes diversos; a colocação dos termos nos enunciados como imagem das opções de enfoque ou das posições discursivas; a eleição do gênero e do tipo textual como indicador da relevância dos itens temáticos e lexicais contemplados no texto etc. (SIMÕES, 2009, p. 78)

É essa representatividade que se busca observar nos textos-corpus a partir da identificação do processo de semiose construída com base na seleção lexical e na 
construção da identidade dos protagonistas das obras de em questão. Com esse intento, importa trazer ao texto a contribuição de um crítico literário, com relação à produção desenvolvida no período histórico em referência neste trabalho. Em sua obra História concisa da Literatura brasileira (1982), Alfredo Bosi, analisando a produção literária dos anos 1930, afirma que eventos mundiais como o socialismo, o freudismo e o catolicismo existencial foram "chaves que serviram para a decifração do homem em sociedade e sustentariam ideologicamente o romance empenhado desses anos fecundos para a prosa narrativa" (BOSI, 2000, p. 389).

Em função disso, outras "chaves" são apresentadas nesta pesquisa, cujo objetivo é investigar os reflexos dos contextos político e socioeconômico da década de 1930 na representação da identidade no âmbito da literatura, mais especificamente em três das obras do autor Graciliano Ramos: São Bernardo, Angústia e Vidas Secas. O regime político-econômico imposto ao povo brasileiro na década de 1930 marcou um período histórico cujas lembranças ecoam na memória nacional. Nesse contexto de abalo das estruturas sociais, situam-se as três referidas obras. Produzidos na década de 1930, os romances fazem parte de um cenário no qual as ações de cunho político e socioeconômico e, consequentemente, as marcas impressas no tecido social podem ter sido determinantes na configuração de novas identidades, representadas no texto literário.

O fato de que a língua reflete não só os processos mais subjetivos como também aqueles que representam as vivências em sociedade é a razão que justifica a abordagem destas investigações. Por isso, as pesquisas foram desenvolvidas no aparato lexical da obra, a partir de uma abordagem semiótica, calcadas nos estudos em torno da temática da Identidade. 
Dessa forma, a análise dos corpus foi feita segundo os estudos desenvolvidos por Simões (2009) no campo da iconicidade verbal, cujos estudos têm comprovado o potencial de significação do aparato lexical do texto escrito e sua importância na construção do significado nos processos de escrita e leitura. São trazidas ainda as contribuições de Hall (2006), Bauman (2005) e Morin (2007) acerca das influências na formação da identidade e em sua crise.

A partir do entendimento de que a formação da identidade do "sujeito sociológico" (Hall, 2006, p. 2) ocorre na interação entre o eu e a sociedade, e que essa identidade preenche o espaço entre o mundo interior e o mundo exterior, o pessoal e o público - influenciando e sendo influenciada pelo meio e, ainda, que essa identidade é refletida nas ações, na linguagem e na arte - acredita-se que as obras citadas configuram uma representação da identidade do povo brasileiro durante o período histórico no qual estão inseridas. Essa abordagem pretende preencher uma lacuna referente à necessária combinação língua/identidade/contexto histórico. Entende-se que esse enfoque tem muito a contribuir não só para a percepção do valor histórico da obra, mas também para um ensino mais profícuo da leitura e da interpretação de textos literários nas salas de aula.

A tese que se buscou comprovar é a de que as obras São Bernardo, Angústia e Vidas Secas, refletem, ainda que não intencionalmente, uma crise na identidade de boa parte do povo brasileiro, provocada pelos acontecimentos vigentes no referido período histórico cujos reflexos foram vivenciados, respectivamente, em três planos: regional, individual e social.

Neste ponto, traz-se uma citação de Benedetto Vecchi na introdução aos estudos de Bauman (2005), quando diz que 
Qualquer que seja o campo de investigação em que se possa testar a ambivalência da identidade, é sempre fundamental distinguir os polos gêmeos que esta impõe à existência social: a opressão e a libertação. (VECCHI, 2005, p. 13)

A opressão, porque condiciona a identificação com o que é externo ao indivíduo; a libertação, porque permite que o indivíduo se manifeste com o que lhe é próprio. Nesse enfrentamento, a linguagem se apresenta como instrumento de manifestação de opinião e de expressão simbólica representativa de aspectos da identidade humana.

Com esse entendimento, investigou-se a forma pela qual a representação da identidade é refletida na configuração do tecido linguístico dos textos-corpus. Para tanto, foram propostas as seguintes questões a fim de nortear as pesquisas: 1) É possível identificar traços de identidade a partir do estudo da iconicidade lexical nas obras em foco? 2) De que modo os signos icônicos e indiciais podem refletir as tensões que fundamentam a construção da identidade (eu X eu, eu X outro, eu X mundo)? 3) As formas icônicas e indiciais levantadas nas obras podem atestar a verossimilhança entre o mundo narrado e o cenário sociopolítico da época na qual as obras são localizadas?

Nessa vertente, o léxico configura a principal abordagem das investigações aqui propostas. Vale ressaltar a importância do texto literário nestas investigações, visto que é legítimo representante da cultura de um povo e, por isso, válido para a análise desenvolvida.

\section{Os resultados}


A abordagem proposta na tese que se buscou resumir neste artigo encontra fundamentação na fala de Simões, quando afirma que o homem lida sem saber com a trindade semiótica - ícone, índice e símbolo. Por isso, a autora considera que esse conhecimento deve ser ensinado desde os primeiros anos de escolaridade, sem que haja apego à nomenclatura. (SIMÕES, 2017, p. 17-18). Os pressupostos dessa teoria têm como objetivo a melhoria da qualidade no ensino de leitura e da produção textual, a partir da identificação das pistas produzidas no ato da escrita e reconstituídas na trama textual, no ato de leitura.

Essa importância decorre do fato de que a prática da leitura está intrinsecamente associada ao desenvolvimento da pessoa e ao exercício da cidadania. Como legítimo representante da cultura de um povo, o texto literário precisa ter participação efetiva nas aulas de Língua Portuguesa. Seja como simples fruição, seja com o fito de uma análise criteriosa, o texto permite que o leitor/aluno desenvolva seu conhecimento enciclopédico, enriqueça seu vocabulário e identifique traços da identidade cultural de um povo. Além disso, a associação do texto literário com informações recebidas no âmbito de outras disciplinas como a História, a Filosofia e a Sociologia, podem ser resgatadas na malha textual, a partir da qual o leitor reforça o conteúdo apreendido.

Antunes afirma que “(...) todas as questões que envolvem o uso da língua não são apenas questões linguísticas; são também questões políticas, históricas, sociais e culturais" (ANTUNES, 2009, p. 21, grifo do autor). Essa afirmação corrobora a necessidade da abordagem linguístico-cultural no ensino de línguas, com vista a um ensino profícuo da Língua Portuguesa. Esse entendimento independe das dimensões do território ou do alcance da língua falada. Entretanto, torna-se ainda mais necessário quando o alcance da língua ocorre num país com as dimensões do Brasil, cuja diversidade exige dos 
profissionais da língua uma visão ampla do seu objeto de estudo, para um ensino consciente.

Para a compreensão do caminho percorrido, destacam-se as questões que nortearam a pesquisa. A primeira questão - É possível identificar traços de identidade a partir do estudo da iconicidade lexical nas obras em foco? - aborda, principalmente, a aplicabilidade da teoria eleita, TIV, na identificação de traços de identidade. As análises em torno dos personagens Paulo Honório, Luís da Silva e Fabiano, apresentaram com detalhes, os traços de personalidade de cada um. Em relação aos dois primeiros, as conclusões foram baseadas no próprio uso linguístico da personagem, visto que ambos os protagonistas também são narradores da própria história, o que tornou possível analisar as realizações da linguagem tanto em suas relações com outras pessoas, quanto no próprio texto da narrativa. A despeito do fato de sua história ter sido narrada por um narrador-observador, a terceira personagem, Fabiano, não ficou muito distante dessa análise, uma vez que o narrador usa o recurso do discurso indireto-livre, possibilitando a identificação da fala da personagem em vários momentos da narrativa.

A aplicabilidade da TIV na identificação dos traços da identidade das personagens pode ser verificada ao longo da tese. Contudo, a resposta à primeira questão pode ser verificada, principalmente, no capítulo do texto original, no qual foram apresentadas as características da identidade das três personagens. O protagonista de São Bernardo, orgulhoso e solitário, tem seu orgulho configurado na necessidade de perpetuação de seu nome com a publicação de sua história; no desejo de "fundação" de uma família; na superstição, que o aprisiona, configurada na crendice do pio da coruja, e na forma de interação com os seus semelhantes. Destaca-se nessa personagem o uso das expressões 
lexicalizadas, a partir das quais pode-se traçar sua identidade em relação aos seus semelhantes, principalmente, em relação à figura feminina.

Protagonista de Angústia, o sentimento de inferioridade de Luís da Silva, é representado, principalmente pela forma como a própria personagem se imagina diante das pessoas e da sociedade. Uma vida caracterizada como "vida de sururu" e na aceitação digna de um "percevejo social". O instinto assassino, o desequilíbrio emocional e a subserviência da personagem também são detectáveis na trama textual, pelos ícones e índices que a compõem. Ressalta-se a extrema importância da organização da narrativa na configuração da identidade conturbada de Luís da Silva. A narrativa vertiginosa, com alternância entre passado remoto, passado próximo, presente e possibilidade de futuro, contribuíram significativamente na percepção da personalidade doentia do protagonista.

O vaqueiro solitário, que protagoniza Vidas Secas, tem sua solidão representada pelo sentimento de não pertencimento e pela opressão sofrida. Essas duas experiências desenvolvem na personagem uma identidade distante de sua humanidade. Sua identidade o aproxima dos animais, com os quais se entende perfeitamente, na mesma proporção que constrói sua não-identidade com os humanos que o rodeiam. Os paradigmas, a partir dos quais se constrói a identidade dos sertanejos aqui representados, são, respectivamente, a alteridade do semelhante, o próprio eu interior e a opressão do sistema político-econômico.

A segunda - De que modo os signos icônicos e indiciais podem refletir as tensões que fundamentam a construção da identidade (eu X eu, eu X outro, eu X mundo)? - busca identificar o modo como as identidades são construídas e como aparecem no tecido textual. Essa questão tem sua resposta construída ao longo dos capítulos 5 e 6 do texto da tese. O perfil das personagens entra em choque com o outro, com o desconhecido, 
com o mundo. Paulo Honório, Luís da Silva e Fabiano enfrentam a crise de sua identidade quando deparam com aquilo que questiona suas certezas. A forma como enfrentam os desafios identifica a subjetividade de cada um. Os ícones e índices identificados nesses enfrentamentos atestam as tensões que fundamentam não só a construção das identidades, mas também a sua crise.

A última questão desenvolvida - As formas icônicas e indiciais levantadas nas obras podem atestar a verossimilhança entre o mundo narrado e o cenário sociopolítico da época na qual as obras são localizadas? - aborda a questão da literatura como reflexo do universo de referência ao qual está, necessariamente, conectada. A resposta positiva a essa questão é calcada em três aspectos distintos, no entanto, complementares. 0 primeiro aspecto é representado pela trilha lexical deixada no corpo do texto direciona o leitor para a percepção do período histórico de referência, principalmente, no que consiste aos fatos linguísticos. O segundo, com base nas abordagens apresentadas no capítulo 4 da tese, com a possibilidade de recepção do texto literário com sua verossimilhança interna, e no entendimento de que a literatura é reflexo da cultura de um povo em determinado período e lugar. O terceiro aspecto fala diretamente às referências explícitas no corpo do texto a eventos históricos ocorridos no período da década de 1930.

Em função do exposto, entende-se que a diversidade linguístico-cultural precisa ser objeto de estudo, não apenas no âmbito acadêmico, mas no âmbito do Ensino Básico, a fim de que os laços linguísticos sejam estreitados, os preconceitos diminuídos e o conhecimento disseminado. Em função disso, a adoção de material pedagógico único, para todo o território nacional, apresenta duas incoerências. Primeiramente, essa unificação não contempla a diversidade cultural e, consequentemente, linguística, 
inerente à realidade brasileira. Posteriormente, percebe-se que a implementação do Plano Nacional de Educação Básica (PNLD) não corrobora os propósitos, definidos pelo mesmo Governo, para a educação nacional. Propósitos preconizados pelos Parâmetros Curriculares Nacionais e pela Lei de Diretrizes e Bases, conforme citado anteriormente.

Destacam-se, pois, dois pontos de extrema importância para o ensino da Língua Portuguesa e da cultura nacional: a relevância das obras analisadas como demonstração da identidade de boa parcela do povo brasileiro e a importância de conhecer/compreender as diversas identidades sem menosprezá-las, mas, ao contrário, entendê-las em seus contextos como tipos brasileiros reais cuja linguagem representa as nuanças socioculturais de nosso povo e de nossa nação. O conhecimento e a compreensão da diversidade linguística estão associados à ideia da poliglossia interna, defendida por Simões e Garcia (2008, p. 165), segundo a qual as "escolhas da variedade linguística (...), do jargão, do léxico e da organização sintático-semântica" são a base do ato discursivo. Ou seja, o ato discursivo é o resultado da congruência do projeto comunicativo do enunciador, do interlocutor, do espaço e do tempo de enunciação, a partir dos quais são direcionadas as escolhas nos âmbitos lexical, sintático e semântico. Segundo esses autores,

O sujeito do discurso se constrói no ato discursivo. Assim sendo, a representação simbólica de suas ideias e ideais sobre um tema será emoldurada pelas características do ato discursivo, quais sejam: sobre o quê se fala (tema), quando se fala (situação têmporo-espacial), a quem se fala (destinatário) e com que intuito (objetivo[s]) (SIMÕES e GARCIA 2008, p. 158)

Entende-se que a competência linguístico-expressional contribui tanto para a formação escolarizada, quanto para a formação cidadã, visto que congrega valores para a constituição do sujeito inserido em uma sociedade formada pela diversidade. Defende-se, 
pois, que o trabalho com a identidade refletida na variação linguística e especialmente demonstrada pelas escolhas vocabulares, então enriquecidas pelas expressões lexicalizadas, pode servir de estímulo não só a novos estudos do mesmo tipo, mas, principalmente, a um trabalho didático-pedagógico mais fortalecido no que tange ao conhecimento da língua do Brasil e de sua riqueza expressional.

\section{Referências}

ANTUNES, Irandé. Língua, texto e ensino: outra escola possível. São Paulo: Parábola editoria, 2009.

BAUMAN, Zygmunt. Identidade: entrevista a Benedetto Vecchi. Tradução: Carlos Alberto Medeiros. Rio de Janeiro: Zahar, 2005.

BOSI, Alfredo. História concisa da Literatura Brasileira. 37 ed. São Paulo: Cultrix, 2000.

FREUD, Sigmund. O mal-estar na civilização. Trad. José Octávio de Aguiar Abreu. Rio de Janeiro: Imago, 1997.

HALL, Stuart. A identidade cultural na pós-modernidade. 11a edição. Rio de Janeiro: DP\&A Editora, 2006.

MORIN, Edgar. 0 método 5: a humanidade da humanidade. Trad. Juremir Machado da Silva. 4 ed. Porto Alegre: Sulina, 2007. 309 p.

RAMOS, Graciliano. Vidas Secas. 27 ed. São Paulo: Livraria Martins, 1970.

. São Bernardo. 18a edição. São Paulo: Martins, 1972.

Cartas. Rio de Janeiro: Editora Record, 1980.

Angústia. 33a ed. Rio de Janeiro, São Paulo: Record, 1987.

SILVA, Tomaz Tadeu da (Org.); HALL, Stuart; WOODWARD, Kathryn. Identidade e diferença: a perspectiva dos estudos culturais. 15 ed. Petrópolis, RJ: Vozes, 2017.

SIMÕES, Darcilia. O Brasil não conhece o Brasil, 2017. Disponível em https://galoa.com.br/blog/o-brasil-nao-conhece-o-brasil. Acesso em 23 de maio/2019.

A ciência, a pesquisa, o método: implicações semióticas. In HENRIQUES, Claudio Cezar e SIMÕES, Darcilia (orgs.). A redação de trabalhos acadêmicos: teoria e prática. 7 ed. Rio de Janeiro: EdUERJ, 2017. 
$\overline{\text { Janeiro: }}$

Iconicidade e verossimilhança. Semiótica aplicada ao texto verbal. Rio de

http://www.dialogarts.uerj.br/arquivos/iconicidade e verossimilhanca.pdf . Iconicidade verbal. Teoria e prática. Rio de Janeiro: Dialogarts, 2009. In http://www.dialogarts.ueri.br/arquivos/iconicidadeverbal.pdf

Língua Portuguesa e cidadania: uma perspectiva multidialetal para o ensino. In Língua e Cidadania: novas perspectivas para o Ensino. SIMÕES, Darcilia e HENRIQUES, Claudio Cezar. Rio de Janeiro: Editora Europa, 2004.

VECCHI, Benedetto. Introdução. In BAUMAN, Zygmunt. Identidade: entrevista a Benedetto Vecchi. Tradução: Carlos Alberto Medeiros. Rio de Janeiro: Zahar, 2005.

Recebido em 28 de maio de 2020.

Aceito em 30 de maio de 2020. 